\title{
Microsurgical Management of Severe Human Adjuvant Disease Due to Mineral Oil Injection
}

\author{
Javier López Mendoza, MD, MBA, FACS*; Jose Telich Tarriba, MD; Arianna Ibarra Reyes, MD \\ Department of Plastic Surgery, Hospital Ángeles del Pedregal, Ciudad de México, Mexico
}

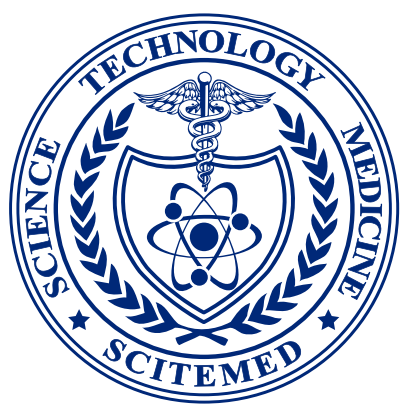

\begin{abstract}
Human adjuvant disease (HAD) is associated with exposure to foreign substances that are injected into patients for cosmetic purposes including silicone, mineral oil, guayacol, and others. The incidence and prevalence of HAD keep increasing. The standard management of HAD starts with pharmacological therapy based on nonsteroid anti-inflammatory drugs, analgesics, and low or moderate doses of prednisone and immunosuppressor drugs. When clinical improvement is achieved, surgical excision is made along with surgical reconstruction. This article presented 3 cases diagnosed with chronic fatigue syndrome, severe skin adjuvant infiltration and skin ulcers. The aggressive debridement and complete removal of foreign materials were performed, and the reconstruction with an intra-operative indocyanine green designed free flap was made to assure stable wound coverage. Post-operative follow-up thermograms were performed and no complication was found. A multidisciplinary approach, including rheumatology, psychiatry, and plastic surgery, is an essential component of providing optimal care to HAD patients. Complete removal of foreign materials is considered the gold standard to diminish the immune reaction against the adjuvant, and a proper reconstruction to guarantee stable coverage with no relapses of disease and a good aesthetic result.
\end{abstract}

\section{INTRODUCTION}

Human adjuvant disease (HAD), first described by Miyoshi in 1973, is associated with exposure to foreign substances that can act as adjuvants, some of which are injected into patients for cosmetic purposes, including silicone, mineral oil, guaiacol, and others [1]. The incidence and prevalence of this disease keep on increasing and over one million persons in Latin America have become victims of these substances [2]. Human adjuvant disease is associated with the exposure to foreign substances that act as foreign bodies (adjuvants), some of which are injected into patients for cosmetic purposes, including silicone, mineral oil, guaiacol, and others. A new term -autoimmune/inflammatory syndrome induced by adjuvants has recently been coined with a process that includes several clinical features previously described by Miyoshi plus other clinical and laboratory parameters related to exposure to diverse external stimuli. Disorders such as siliconosis, Gulf War syndrome, macrophagic myofasciitis syndrome, sick building syndrome, and post-vaccination syndrome have been included in autoimmune/inflammatory syndrome induced by adjuvants. Disorders such as Spanish toxic oil syndrome and Ardystil syndrome could also be included [3].

The standard management starts with pharmacological therapy based on non-steroidal anti-inflammatory drugs, analgesics, and low or moderate doses of prednisone and immunosuppressor drugs, for example, azathioprine or chloroquine; when there is an improvement of the clinical manifestations, they proceed to surgical excision totally or partially and surgical reconstruction.

In Mexico, Dr. Fernando Ortiz Monasterio (Department of Plastic Surgery, General Hospital in Mexico) created an algorithm with multidisciplinary management (Figure 1), expanding the knowledge of the natural history of the disease, the proper medical and surgical treatment, as well as its prognosis [4]. It was a systematic management protocol including 504 patients, of which, 128 patients received surgical treatment, including 40 (31.25\%) male and $88(68.7 \%)$ female. In 86 of the cases, the substances were injected into the buttock, 23 cases in breasts, 11 cases in legs or/and thighs, and 8 cases in the facial area. They made diagnoses with a skin biopsy, Magnetic resonance imaging, and chest X-ray. A multidisciplinary approach with rheumatology, psychiatry, and plastic surgery was performed to decide if the patient was a candidate for a reconstructive procedure or conservative treatment (Figure 2).

In this article, we presented 3 cases of lower extremities HAD treated by the extensive excision and reconstructed with the free flap with good results including one case diagnosed with chronic fatigue syndrome and severe skin adjuvant infiltration, and 2 patients including skin ulcers. The aggressive debridement and complete removal of foreign materials were mandatory to control the disease, and reconstructed with an indocyanine green (ICG) designed free flap can assure the stable wound coverage. Post-operative follow-up with thermography was made and no complications arose. No need for further medical treatment for the human adjuvant disease in two patients and considerably diminished doses in the last patient.

\section{CASE REPORTS}

\section{Case 1}

A 47-year-old female had a history of biomaterial injection 20 years ago in bilateral lateral thighs. She suffered from multiple local reactions 14 years after the infiltration; referring local pain and discomfort when sitting, the skin color changed, thickening of the skin, swelling, local hardening, gravity displacement, and intermittent fever episodes in that area were also noted. Systemic symptoms including chronic fatigue, myalgia, and arthralgia managed with steroids routinely. The physical examination showed a well-defined $15 \times 5 \mathrm{~cm}$ mass located on the distal lateral right thigh, associated with edema, erythema, and hyperpigmentation at bilateral thighs (Figure 3). The Magnetic resonance imaging (MRI) of the legs revealed hyperintensity areas in the subcutaneous tissue located in the distal third of the lateral thigh without muscle involvement.

After the surgical en bloc resection of the necrotic and inflammatory mass of the affected area made until the muscular fascia, the skin and soft tissue 


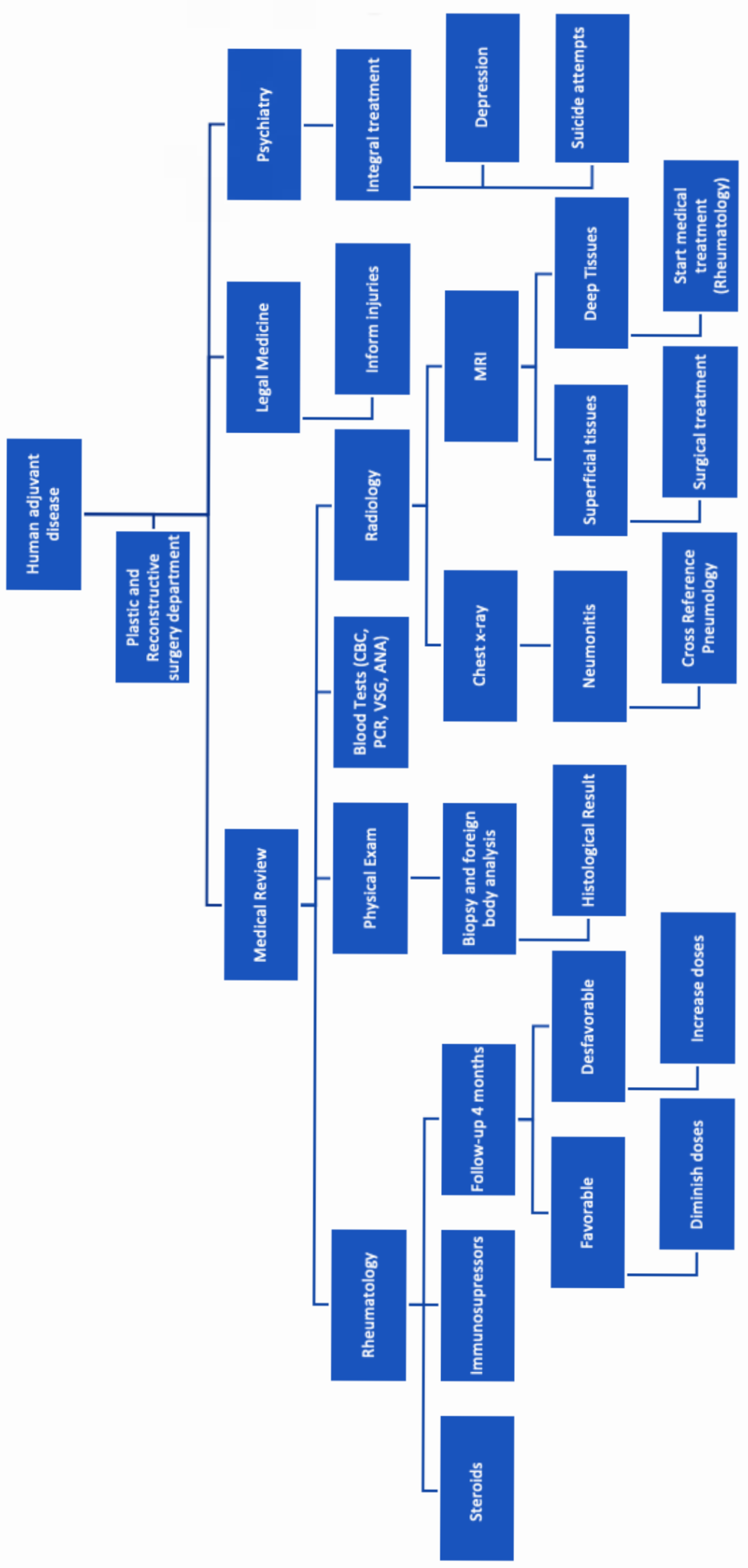

Figure 1. Dr. Fernando Ortiz Monasterio department approach of human adjuvant disease. 


\section{CASE REPORT}

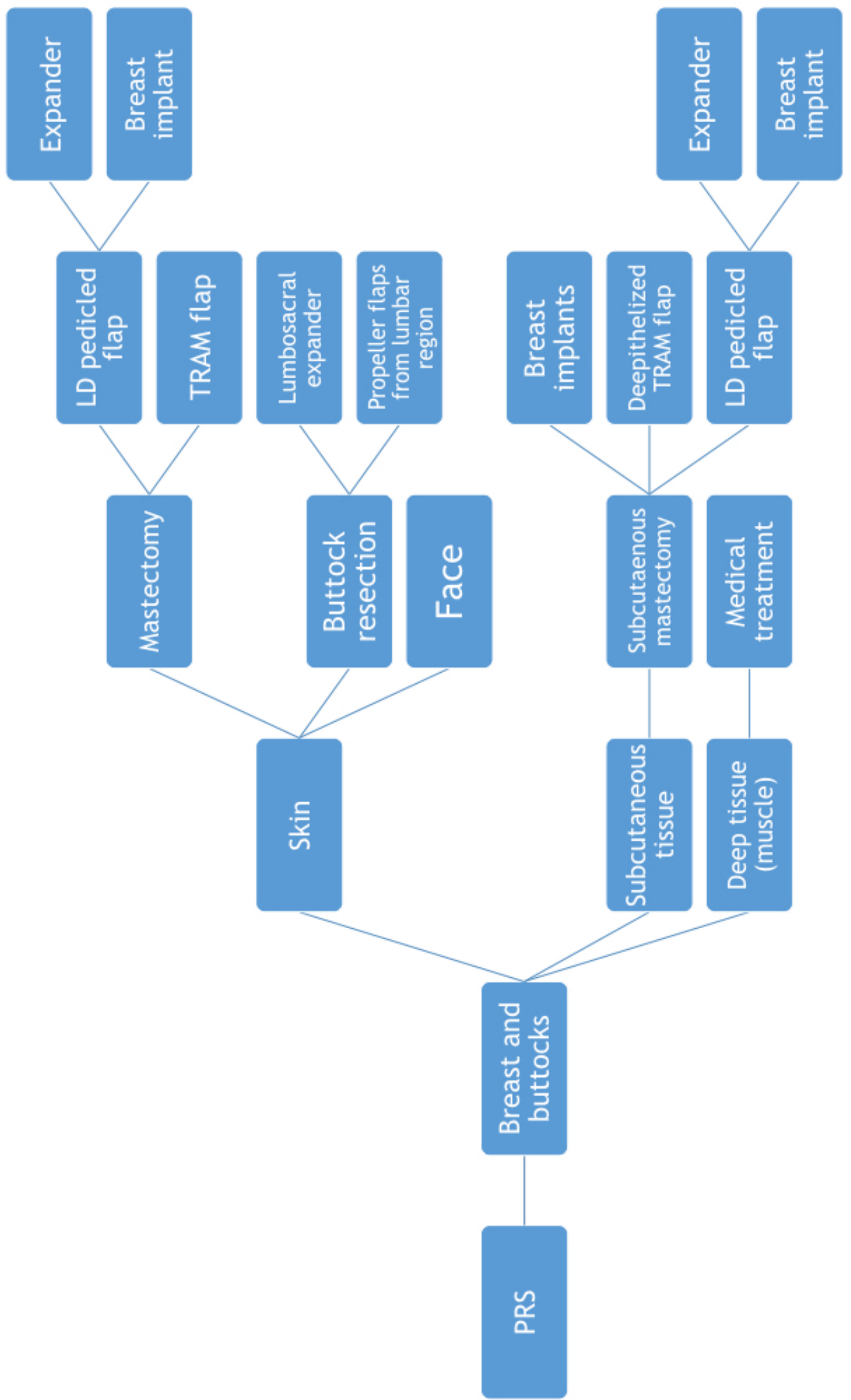

Figure 2. Surgical management of human adjuvant disease according to the affected body area. 


\section{CASE REPORT}

\begin{tabular}{|c|c|c|c|}
\hline Study & Number of cases & Treatment & Complications \\
\hline Kumagai et al., 1979 [5] & 9 & 8 pharmacological therapy; 1 bilateral mastectomy & Not specified \\
\hline Brozena et al., 1988 [6] & 2 & 1 pharmacological; 1 bilateral Mastectomy & Partial necrosis flap \\
\hline Torres et al., 2010 [7] & 110 & $\begin{array}{l}15 \text { pharmacological therapy; } 95 \text { surgical resection ad } \\
\text { direct closure vs. microsurgery (TRAM, DIEP, lattisimus } \\
\text { dorsi flap, lumbar perforator flaps) }\end{array}$ & $\begin{array}{l}2 \text { deaths; } 6 \text { partial or total suffer of nipple-areola } \\
\text { complex }\end{array}$ \\
\hline Torres et al., 2010 [7] & 279 & Not specified & Not specified \\
\hline Vera-Lastra et al., 2012 [8] & 50 & 50 pharmacological therapy; 40 surgical resection & $\begin{array}{l}20 \text { depression; } 8 \text { severe autoimmune disease; } \\
4 \text { deaths }\end{array}$ \\
\hline Gordillo-Hernández et al., 2013 [3] & 504 & $\begin{array}{l}376 \text { pharmacological therapy; } 128 \text { surgical resection } \\
\text { and direct closure vs. microsurgery }\end{array}$ & Not specified \\
\hline Watad et al., 2017 [9] & 300 & $\begin{array}{l}107 \text { glucocorticoids; } 57 \text { DMARD; } 4 \text { biological } \\
\text { treatment; } 3 \text { etarnercept; } 1 \text { infliximab; } 15 \text { Intravenous } \\
\text { immunoglobulin }\end{array}$ & Not reported \\
\hline
\end{tabular}

DIEP, deep inferior epigastric artery perforator; DMARD, disease-modifying antirheumatic drug; TRAM, transverse rectus abdominis myocutaneous.

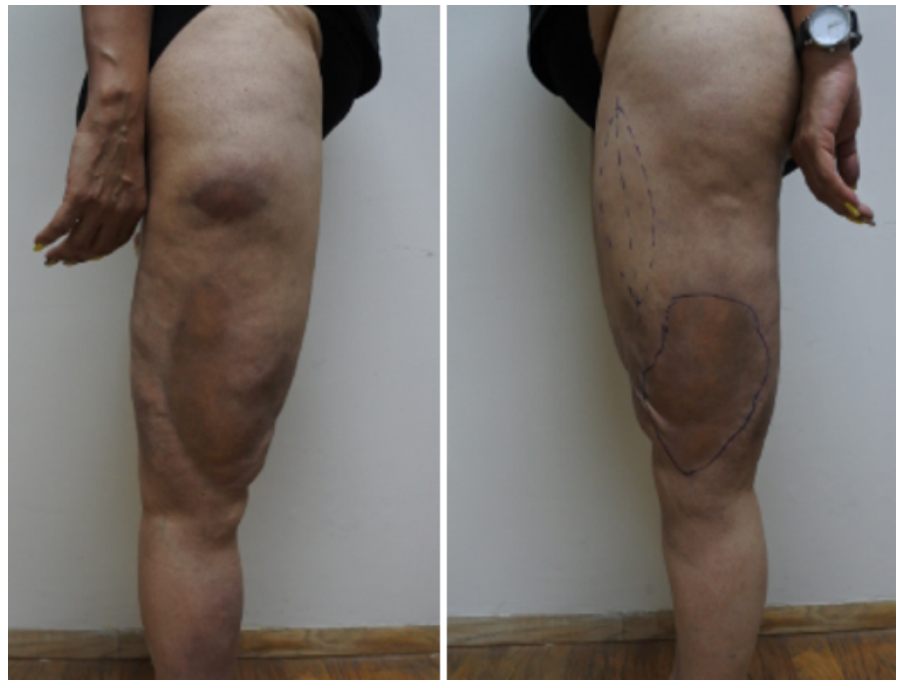

Figure 3. Bilateral thighs with a $15 \times 5 \mathrm{~cm}$ tumor on the distal lateral right thigh. The tumor was well defined, associated with edema, erythema, skin induration, and hyperpigmentation.
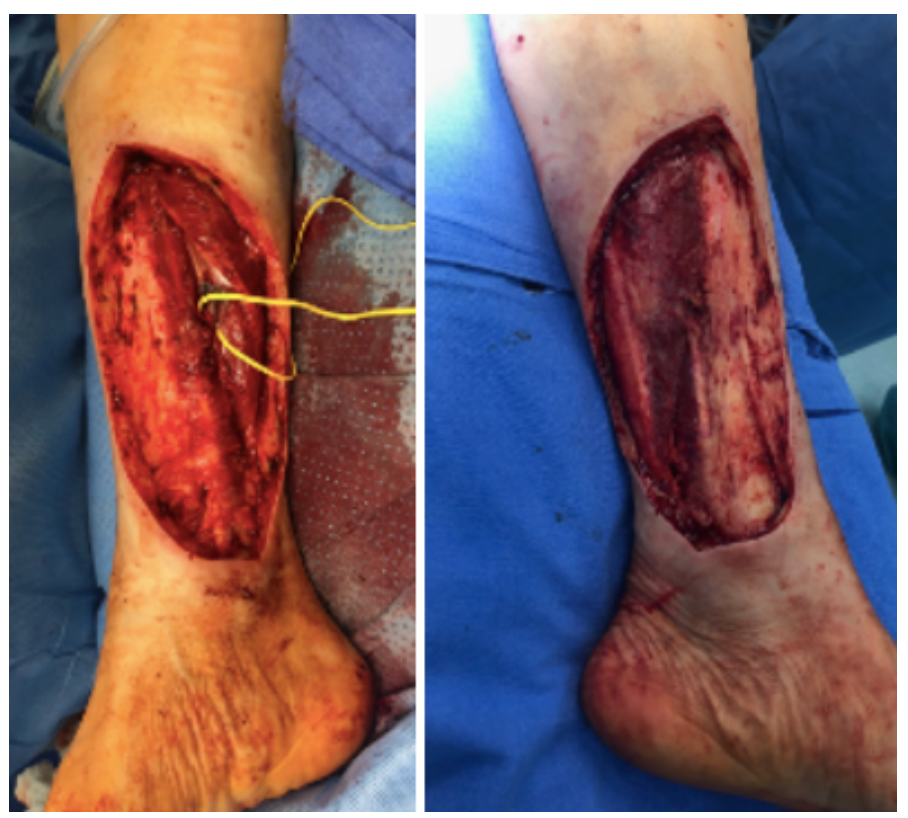

Figure 4. En block resection of infiltrated skin and bilateral final defects of case 2.
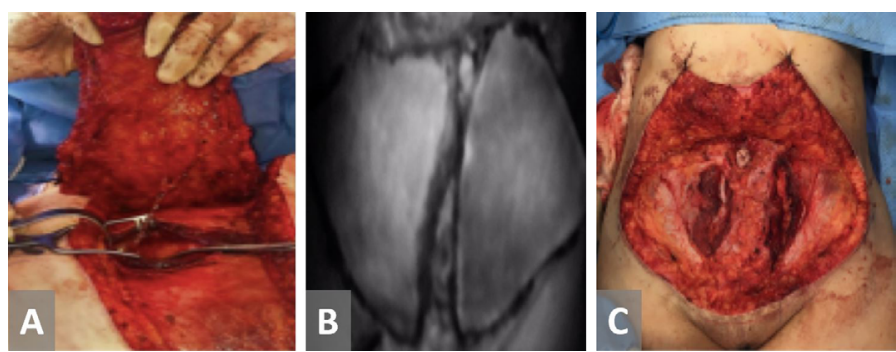

Figure 5. Fluorescence technology using green indocyanine for perfusion assessment during surgery and the final result of the abdominal wall. (A) Harvest of deep inferior epigastric perforator flap. (B) Perfusion assessment of the flaps using green indocyanine. (C) Final result of the abdominal wall.



Figure 6. Bilateral lower legs with skin infiltration, erythema, and skin induration. An 3x3 $\mathrm{cm}$ ulcer was located on the left lower leg with exposed adjuvant and soft tissue. 


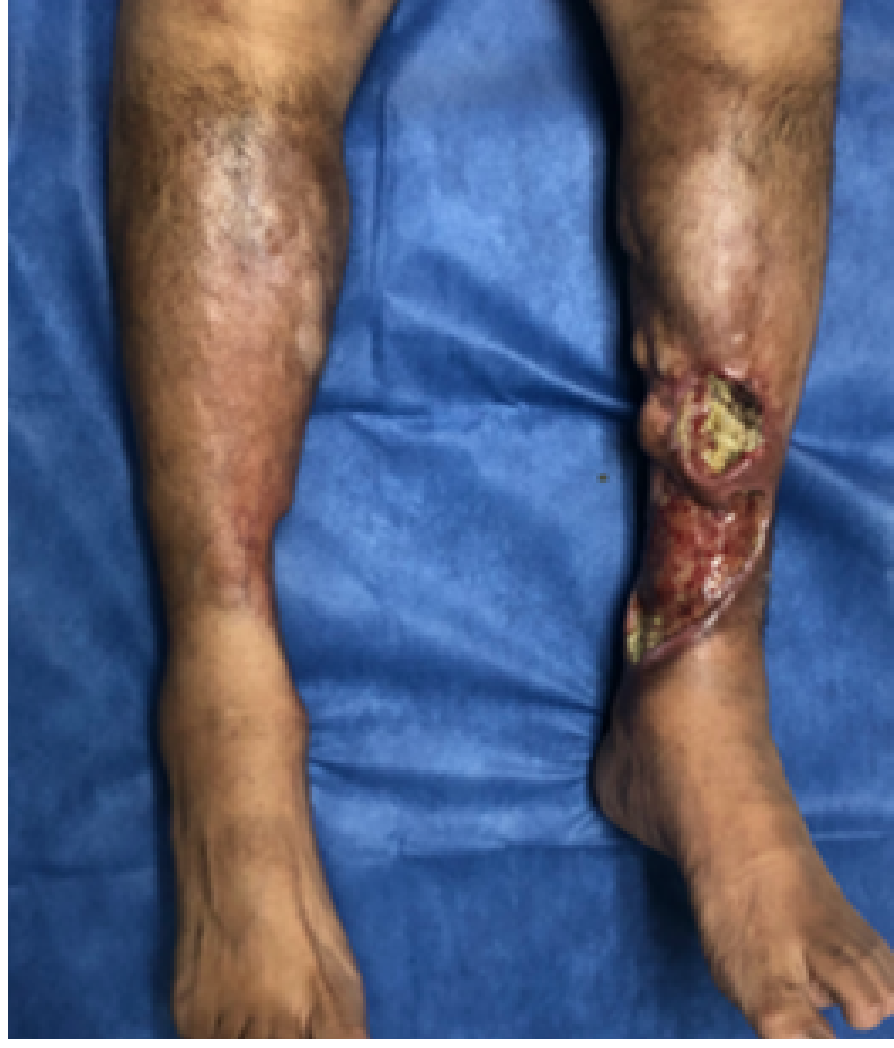

Figure 7. Bilateral lower leg infiltration with a severe ulcer at left lower leg.

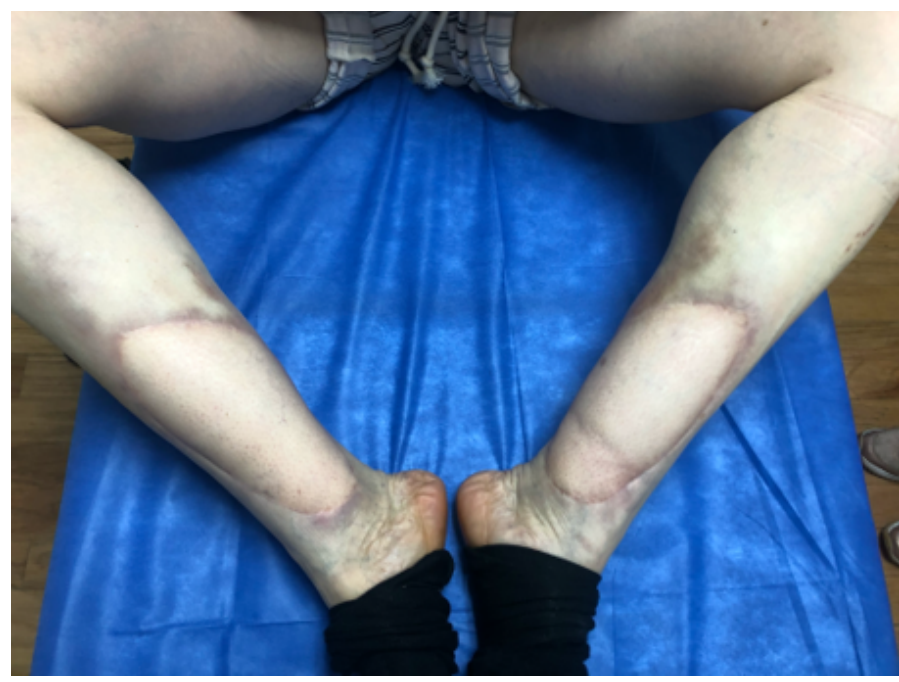

Figure 8. Six months follow-up clinical result of the patient from Case 2.

defect were measured $18 \times 6 \mathrm{~cm}$ bilaterally. The deep inferior epigastric artery perforator (DIEP) flap (Figure 4) was designed and harvested, split into two for bilateral defect reconstruction. The perfusion of both flaps were performed by fluorescence technology with green indocyanine, infrared cameras, ICG designed flaps, and the thermal imaging using SEEK infrared camera (Figure 5). The post-operative course was uneventful, and the patient discharged five days after the surgery with no need for further medical treatment for HAD.

\section{Case 2}

A 53 years old female had a history of foreign body injection 32 years ago at bilateral lower legs for calf augmentation. However, she suffered from skin irritation, erythema, swelling, and pain eight years ago; furthermore, three months ago, she noted an ulcer at the left lower leg. The systemic symptoms included chronic fatigue, myalgia, and arthralgia. The physical examination revealed a $13 \times 8 \mathrm{~cm}$ well-defined infiltrated and erythematous area at bilateral distal lower legs. The left field presented with a $3 \times 3 \mathrm{~cm}$ ulcer (Figure 6). MRI of the legs revealed hyperintensity areas in the subcutaneous tissue located in the bilateral calves without muscle involvement.

After the en bloc resection of the involved area of the necrotic and inflammatory tissue until muscular fascia, the skin and soft tissue defect of $14 \times 9 \mathrm{~cm}$ with exposure of bilateral tibia were noted bilaterally (Figure 7). Because of the previous anterior abdominal wall liposuction history, in this case, bilateral anterolateral thigh (ALT) flaps were designed and harvested for the defect coverage and repaired the anterior tibial vessels.

The post-operative monitoring was done by clinical examination; doppler signal and SEEK thermographic camera as an adjunctive tool; no complications recorded. The patient discharged on post-op day 5 with no need for further medical treatment for HAD. The six months follow-up (Figure 8) revealed a satisfactory functional and aesthetic outcome.

\section{Case 3}

A 59 years old female had a history of mineral oil injection 45 years ago at bilateral lower legs for calf augmentation. She had severe skin infiltration and ulceration at both lower legs 18 years ago, which was managed initially with skin grafts. At the left lower leg, she required a soleus muscular flap and skin graft to cover an ulcer 14 years ago. She then had multiple relapses of the ulcer and it was managed conservatively. Unfortunately, a severe relapse of this ulcer occurred and over infection with pseudomonas developed a major ulcer. Systemic symptoms included as previous patients. The physical exam revealed a well delimitated $15 \times 9 \mathrm{~cm}$ ulcer at the lower left leg, with ill granulation tissue, exposure of adjuvant at the borders of ulcer, and moderate exudative fluid. Tissue cultures revealed pseudomonas aeruginosa, managed with Zavicefta (ceftazidime/avibactam).

After en bloc resection of ulcer, granulation tissue, and foreign materials until tendons and bone with free margin, the tissue defect was measured $20 \times 11 \mathrm{~cm}$ with exposure of tibia. Since the patient also had the previous history of a tummy tuck, an ALT flap was designed and harvested for wound coverage and repaired the anterior tibial vessels under magnification.

The post-operative follow-up was made clinically and by thermography with FLIR One thermographic camera as an adjunctive tool, and no complications recorded. The patient discharged on the third post-operative day. After two months, the patient revealed a satisfactory functional outcome. Unfortunately, the other leg was still infiltrated with mineral oil, and this was the main reason she was still on treatment for HAD.

\section{DISCUSSION}

Surgical treatment in HAD continues to be a challenge, and it is arising in the Latin American population with a report of more than one million people affected. However, nowadays, there are still few reports of surgical management for this disease (Table 1). It is considered that the full removal of adjuvants would improve the symptoms and local conditions of the affected patients. With the experienced microsurgical reconstruction, we can guarantee the removal of $100 \%$ of the foreign body in the region with proper wound coverage.

An ICG designed flap can guarantee a well-defined vascularized flap, with no necrotic edges or wound problems as dehiscence that are common in patients with infiltration of adjuvants (due to dermis infiltrated or long last use of steroids). Also, the postoperative follow-up with thermographic cameras is a handy and economical tool to decrease the need for a specialized nurse or doctor.

Nowadays, with microsurgical advances, the reconstruction of defects arising after resection in a block of the affected tissue, due to the infiltration of modeling substances, is becoming worldwide accepted, especially in a patient with severely impaired quality of life. Multidisciplinary management, including rheumatology service, can improve the quality of life of this kind of patient. 


\section{CONCLUSION}

The complete removal of foreign material is the gold standard to diminish the immune reaction against the adjuvant, and proper reconstruction guarantees stable coverage with no relapses of the disease, better control of the immunologic response, and an acceptable functional and aesthetic result.

\section{ARTICLE INFORMATION}

*Correspondence: Javier López Mendoza, MD, MBA, FACS. Department of Plastic Surgery, Hospital Ángeles del Pedregal, Camino de Sta. Teresa 1055-S, Heroes de Padierna, Héroes de Padierna, La Magdalena Contreras, 10700 Ciudad de México, CDMX, Mexico

Received:Jan. 16, 2020; Accepted: May 13, 2020; Published: Dec. 09, 2020

DOI: $10.24983 /$ scitemed.imj.2020.00138

Ethics Approval and Consent to Participate: The study is in accordance with the ethical standards of the 1964 Helsinki declaration and its later amendments or comparable ethical standards.

Funding: The study did not receive any specific grant from funding agencies in the public, commercial, or not-for-profit sectors.

Conflict of Interest: The authors report no financial or other conflict of interest relevant to this article, which is the intellectual property of the authors.

Copyright (c) 2020 The Authors. This is an open-access article distributed under the terms of the Creative Commons Attribution 4.0 International License (CC-BY).

\section{REFERENCES}

1. Torres GB, Burgos VR, Medrano RG, Priego BRB: Instrumento para evaluar y estadificar el daño producido por la infiltración de sustancias modelantes. Cir Plast 2010;20(3):105-111.

2. Coiffman F. A new disease: latrogenical alogenosis. Cir plást iberolatinoam 2008;34(1):1-10.

3. Gordillo-Hernández J , Alegre-Tamez E, Torres-Baltazar I, Mendieta-Espinosa MJ, Sastré-Ortiz N. Multidisciplinary management of adjuvant human disease by injection of modeling substances. Cir plást iberolatinoam 2013;39(3):269277.

4. Alijotas-Reig J. Human adjuvant-related syndrome or autoimmune/inflammatory syndrome induced by adjuvants. Where have we come from? Where are we going? A proposal for new diagnostic criteria. Lupus 2015;24(10):1012-1018.

5. Kumagai $Y$, Abe C, Shiokawa Y. Scleroderma after cosmetic surgery: four cases of human adjuvant disease. Arthritis Rheum 1979;22(5):532-537.

6. Brozena SJ, Fenske NA, Cruse CW, et al. Human Adjuvant Disease Following Augmentation Mammoplasty. Arch Dermatol 1988;124(9):1383-1386.

7. Torres GB, Medrano RG, Priego BR, Peláez BI, Burgos VR. Enfermedad por la infiltración de sustancias modelantes con fines estéticos. Cir Plast 2010;20(3):124132.

8. Vera-Lastra O, Medina G, Cruz-Dominguez MP, et al. Human adjuvant disease induced by foreign substances: a new model of ASIA (Shoenfeld's syndrome). Lupus 2012;21(2):128-135.

9. Watad A, Quaresma M, Bragazzi NL, et al. The autoimmune/inflammatory syndrome induced by adjuvants (ASIA)/Shoenfeld's syndrome: descriptive analysis of 300 patients from the international ASIA syndrome registry. Clin Rheumatol 2018;37(2):483-493. 